\title{
Research and evaluation of the effectiveness of e-learning in the case of linear programming
}

\author{
Ljiljana Miletić ${ }^{1, *}$ and Goran Lešaja ${ }^{2}$ \\ ${ }^{1}$ Gimnazija Požega \\ Street dr. F. Tudmana 4.A \\ 〈liljana.mileti2@gmail.com〉 \\ ${ }^{2}$ Georgia Southern University \\ 1332 Southern Drive, Statesboro, Georgia 30458, USA \\ 〈goran@geoergiasouthern.edu
}

\begin{abstract}
The paper evaluates the effectiveness of the e-learning approach to linear programming. The goal was to investigate how proper use of information and communication technologies (ICT) and interactive learning helps to improve high school students' understanding, learning and retention of advanced non-curriculum material. The hypothesis was that ICT and e-learning is helpful in teaching linear programming methods. In the first phase of the research, a module of lessons for linear programming (LP) was created using the software package Loomen Moodle and other interactive software packages such as Geogebra. In the second phase, the LP module was taught as a short course to two groups of high school students. These two groups of students were second-grade students in a Croatian high school. In Class 1, the module was taught using ICT and e-learning, while the module was taught using classical methods in Class 2. The action research methodology was an integral part in delivering the course to both student groups. The sample student groups were carefully selected to ensure that differences in background knowledge and learning potential were statistically negligible. Relevant data was collected while delivering the course. Statistical analysis of the collected data showed that the student group using the e-learning method produced better results than the group using a classical learning method. These findings support previous results on the effectiveness of e-learning, and also establish a specific approach to e-learning in linear programming.
\end{abstract}

Key words: linear programming, simplex method, interior point-method, Loomen Moodle - course management system, GeoGebra - dynamic geometry program, action research

Received: October 10, 2014; accepted: March 26, 2016; available online: March 31, 2016

DOI: $10.17535 /$ crorr.2016.0008

\section{Introduction}

Information and communication technology is important in the development of various scientific disciplines and mathematics, enabling their widespread use.

${ }^{*}$ Corresponding author. 
Mathematical content is largely abstract and difficult to understand. Computers can assist in visualizing such content. "While physical objects become more abstract when modelled onscreen (e.g. science simulation), mathematical objects, already inherently abstract, become concrete" [8].

The effectiveness of e-learning was investigated using an LP lesson module as an example. The less module provides an overview of the development of the linear programming problem, linear programming model, theory of linear programming, counting vertices - enumeration method, geometric method, 2 D, simplex method, Charnes' M-method [15], the two-phase simplex method [15], and finally, the method of interior points [9, 10]. Software that aided learning linear programming included Excel Solver, Lindo, Winqsb and Simplex apple. The basics of running GeoGebra was also explained. The module implemented in the software package for online learning is Loomen Moodle.

To study the effectiveness of e-learning, action research methodology was used, bringing about a different approach to teaching. The empirical part of the research was carried out in the two sophomore classes, Class1 and Class2 at Požega High School as already mentioned. The learning outcomes, assessment criteria and evaluation of student achievement were defined. Students participated freely in the research which was organized into three cycles, where each cycle required a knowledge test and a final exam. Both classes were taught the same linear programming content using action research. Action research results are usually directly applicable in teaching practice as they are obtained performed "on the spot" $[11,14]$. Most modern professions, especially teaching, are faced with complex practical requirements where problems cannot always be predicted in advance, and furthermore, offer clear solutions and solutions that can be applied. Nowadays, school teachers are active participants in the research process. Action research is a systematic process of observation and description, planning, action, reflection, evaluation, modification, where a combination of action and research can provide new insights for improving the quality of educational practices [4, 11]. Although previous research has clearly proven the advantage of action research and e-learning over traditional learning $[1,7,17]$, the effectiveness of e-learning in operational research topics, such as linear programming methods, have not been investigated adequately to date. Besides addressing this gap, this paper also aims to analyze the manner in which different linear programming methods are incorporated by students in an e-learning environment.

The material covered in the module is not part of the regular educational curriculum. An important premise of the research was to establish that there were no statistically significant differences in prior knowledge and previous successes between the two student groups. This was determined by collecting data and testing the knowledge of students in areas relevant to the material taught in class. The only difference was that students in class 2 a received all the necessary materials in digital form via Loomen Moodle and used computers in the classroom, whereas students in class $2 \mathrm{~b}$ received their materials in paper 
form and were taught in the classroom using a board and exercise books. After each cycle, all the students were given tasks. Students in class 2 a submitted these digitally via Loomen Moodle from home, whereas students in class $2 \mathrm{~b}$ brought their homework to school and submitted it in paper form. The results were analyzed statistically. The t- test was used to compare the results. Given that action research was used, the qualitative analysis of results was more important than the quantitative statistical analysis. Action research included three critical friends who followed the course, and a number of useful tips was obtained from them.

At the end of the course, statistical analysis of learning effectiveness was performed and the result compared for both classes in order to test the starting hypothesis which states: Effective usage of information and communication technology for interactive learning of linear programming improves the understanding and adoption of materials and student learning outcomes.

\section{Previous Research}

E-learning and education provides temporally and spatially (time-wise and space-wise) flexible access to up to date multimedia and interactive teaching materials and allows dynamic use of the Croatian and international repository of educational content, digital libraries, archives and museums. ICT enables personalization of educational content to the individual needs of students, and supports collaborative learning and team work. Accordingly, availability is increased for a wider range of participants (participants with special needs, students in remote locations, foreign students, etc.). The growth of e-learning and education increases the role and importance of teachers as mentors, coordinators and instigators of the educational process. E-learning shifts the center of the learning process to the student, who then assumes an active role and responsibility for learning outcomes [12]. The positive outcomes of elearning, especially web-based learning in teaching international students in Russia were highlighted by Yanuschik et al. [17]. Dečman [7] tested and evaluated the applicability of the Unified Theory of Acceptance and Use of Technology (UTAUT) in a specific mandatory e-learning environment in higher education in Slovenia. His research has shown that a student's gender and previous education influence the acceptance and use of ICT in learning. The effectiveness of e-learning is also point out in [1].

In Croatia, part of the e-content has been developed to facilitate educational processes in primary and secondary schools, and made available on the national portal Nikola Tesla, where the Croatian Academic and Research Network (CARNet) provides information and infrastructural support for elearning, as well as a system for managing educational content and a videoconferencing system. Besides the existing e-aids, systematic support should be given to developing other e-tools, for example, peer-reviewed e-books, multimedia demonstration lessons, exercises, simulations, expert teaching 
systems, development of e-learning software tools at all levels of education [12]. In secondary schools, e-learning is still not utilized at a satisfactory level and very often even it is void of an appropriate form. According to the results of an input survey conducted upon commencement of research, none of the participating students had attended an online course before.

Research conducted at the Marko Marulić Secondary School in Slatina [16] addressed three specific problems encountered by the school The first problem is the lack of teacher training for working with students incorporating a modern teaching approach and modern technologies. Another problem is insufficient knowledge of English by teachers that is required for modernizing teaching and more intensive use of the Internet. The third problem is the lack of material resources needed to support modern teaching methods. A discussion concerning problems relating to the introduction of e-learning in secondary schools is given in [2]. Some of the conclusions are:

(1) For now, only a relatively small number of secondary school teachers have expressed interest in introducing technology in the educational process. The reasons are twofold: first, the introduction of new technologies and methods is not mandatory, and secondly, there is a lack of readily available appropriate multi-media materials that teachers can use. Consequently, they would have to create the materials themselves which requires a lot of effort and time, time they do not have or which is insufficiently valued [2].

(2) If viewing e-learning as a learning continuum, the conclusion is that computers are only used as a teaching aid in secondary schools [2]. In some rare cases, there is an indication of combined teaching techniques in a way that students use materials on web or on CD-ROM, while communicate with the teacher by e-mail or on-line forum. For more substantive shift to online teaching in secondary education teachers should be more educated in methodics and technology.

The second important element of the research was the use of action research methodology which has recently been gaining popularity. Most modern professions, especially teaching, face complex practical requirements where problems cannot always be predicted in advance. Nowadays, school teachers have become active participants in research processes. Action research is the systematic process of observation and description, planning, action, reflection, evaluation, and modification. By combination action and research, new insights into improving the quality of educational practices are obtained [5, 6, 14]. Although action research is under-represented in teaching practice, the situation has recently changed. The teachers are trying to get to know students better and involve them in becoming action researchers, and to start utilizing increasingly online courses and e-learning. In Croatia, the biggest contribution to the development of action research has come from Bognar $[4,5,6]$. Under his mentorship, students at the Teacher Training Faculty in Osijek have been exploring active learning methods in classroom teaching, including action 
research [6]. Lately, an increasing number of teachers have begun using action research in their teaching as noted in [5]. Bjelanović Dijanić, a mathematics and computer science teacher at Čazma High School, has been specifically incorporating action research in teaching mathematics [3]. The author in [3] claims that learning mathematics aided by computers and the dynamic geometry software GeoGebra and using methodically designed, interactive educational materials in digital form guarantees full participation of all students in classes, increases motivation in learning mathematics, encourages selfdiscovery and cooperation among students. Importantly, students should work alone or in pairs on computers, and endeavor to gain new insights. Retention of knowledge acquired in this manner will be greater, students will better understand the material rather than rely on memorization, and they will also have better problem-solving skills.

\section{Methodology}

\subsection{Learning cycles in the Linear Programming module of lectures}

The first phase of the project involved designing a module of linear programming lessons. The module was divided into three lesson groups that served as the basis for three cycles within the course, as recommended by action research method [3].

In both classes, students were given the same learning materials. In Class1, the material was in digital form and provided via Loomen Moodle, whereas Class 2 received the materials in paper form as worksheets. In all cycles, the students were given homework, and were also required to solve crossword puzzles and quizzes in conjunction with each taught unit. At the end of each cycle, students took a knowledge test. The students in each cycle were awarded a certain number of points based on content learning activities. Students were informed of the evaluation criteria at the beginning of the course.

The first cycle of the course referred to the linear programming problem and theory. Topics included a brief overview of the development of LP, the LP model, basic LP theory in addition to the main theorems, duality, geometric representation and solution of two-dimensional (2D) LP problems. Students in Class 2 drew a feasible region in an exercise book and the objective function. Students in Class 1 drew the feasible region using GeoGebra, dynamic geometry software. While working in GeoGebra, students could see the feasible region and move parallel level lines through the vertices of the feasible region. This enabled them to readily see in which vertex the objective function achieved a minimum or maximum for a given problem. Examples of the completed GeoGebra applets can be viewed at the following link: http://www.geogebratube.org/student/m88378. 
The second cycle of the course relates involves the simplex method. Students were taught how to solve problems using simplex tables. In addition, they also learnt the Charne's M-method, and the two-phase simplex method. The students in Class 1 who used ICT were introduced to several popular LP solvers such as Excel Solver, Lindo, and Winqsb.

The third cycle of the course describes a relatively new method known as the method of interior points. The method is fundamentally based on Newton's method. The algorithm is presented and explained, and then applied in solving a few simple examples.

The LP lecture module was implemented using the Loomen Moodle elearning system. Students in Class1 were added as course users. The course was made available at all times and at any place, and can still be found at the following link: https://loomen.carnet.hr/course/view.php?id=2746. After going through all three cycles, students solved a demo exam which prepared them for the final exam given at the end of the course.

\subsection{Interior-Point Method used in the third learning cycle}

Since the interior-points method (IPM) for solving LP problems are not as common used as the simplex method (SM), here we will present a novel modification of IPM that ties well with simplex method.

IPM is based on solving a Newton-type system at each iteration. At first, the system is much larger than the system used in SM. However, it can be reduced to a system of the same size as in SM. This reduction is known as normal equations reduction. It is very important as it illustrates to students that systems of comparable size are solved in both methods.

Specifically, the original Newton-type system is given by

$$
\left[\begin{array}{ccc}
A & 0 & 0 \\
0 & A^{T} & I \\
S^{k} & 0 & X^{k}
\end{array}\right]\left[\begin{array}{l}
d_{x} \\
d_{y} \\
d_{s}
\end{array}\right]=\left[\begin{array}{c}
r_{P}^{k} \\
r_{D}^{k} \\
-X^{k} s^{k}+\gamma \mu_{k} e
\end{array}\right] .
$$

The system can be reduced to the system

$$
M d_{y}=r
$$

where

$$
\begin{aligned}
M & =A\left(S^{k}\right)^{-1} X^{k} A^{T}, \\
r & =b+A\left(S^{k}\right)^{-1}\left(X^{k} r_{D}^{k}-\gamma \mu_{k} e\right) .
\end{aligned}
$$

The size of the system that leads to the solution of $d_{y}$ is comparable to the size of the existing system when using SM. Since $d_{s}$ and $d_{x}$ are obtained from backward substitutions 


$$
\begin{aligned}
& d_{s}=r_{d}^{k}-A^{T} d_{y}, \\
& d_{x}=-x^{k}+\left(S^{k}\right)^{-1}\left(\gamma \mu_{k} e-X^{k} d_{s}\right),
\end{aligned}
$$

the number of computations per iteration in IPM and SM are comparable.

The second modification involves calculating the step size along the Newton direction. Originally, the step size is calculated to insure that the new iterate lies within a certain neighborhood of the central path. Theoretically, this importantly ensures convergence of the IPM. We simplified the calculation of the step size by enforcing only the positivity requirement for the new iterate in which case the calculation of the step size is almost exactly the same as the minimal ratio test in SM. Based on this simplification, convergence is not guaranteed, but it works well in practice, and problems rarely occur for certain ill-conditioned problems [9].

The step size is chosen so that the positivity of $X$ and $S$ are preserved when updated. As in SM, $\alpha^{\max }$ is a maximum possible step size until one of the variables becomes 0 . Hence,

$$
\alpha^{\max }=\max \left\{\alpha \geq 0: x^{k}+\alpha d_{x} \geq 0, s^{k}+\alpha d_{s} \geq 0\right\} .
$$

In practice $\alpha^{\max }$ is calculated as follows:

$$
\begin{aligned}
& \alpha_{P}^{\max }=\min \left\{-\frac{x_{i}}{\left(d_{x}\right)_{i}}:\left(d_{x}\right)_{i}<0, i=1, \ldots, n\right\}, \\
& \alpha_{D}^{\max }=\min \left\{-\frac{s_{i}}{\left(d_{s}\right)_{i}}:\left(d_{s}\right)_{i}<0, i=1, \ldots, n\right\}, \\
& \alpha^{\max }=\min \left\{\alpha_{P}^{\max }, \alpha_{D}^{\max }\right\},
\end{aligned}
$$

which is similar to a minimal ratio test for SM. Since we do not allow any of the variables to be 0 , we take

$$
\alpha_{k}=\min \left\{1, \theta \alpha^{\max }\right\},
$$

where $\theta \in(0,1)$. The usual choice of $\theta$ is $\theta=0.9$ or $\theta=0.95$.

The outline of the IPM is presented below. 


\section{Algorithm (Simplified IPM) \\ Initialization:}

1. Choose $\beta, \gamma \in(0,1)$ and $\varepsilon>0$. Choose $\left(x^{0}, y^{0}, s^{0}\right)$ such that $x^{0}=s^{0}=e$ and $y^{0}=0$.

2. Set $k=0$.

Step:

3. Set $r_{P}^{k}=b-A x^{k}, \quad r_{D}^{k}=c-A^{T} y^{k}-s^{k}, \quad \mu_{k}=\frac{\left(x^{k}\right)^{T} s^{k}}{n}$.

4. Check the termination. If

then terminate.

$$
\left\|r_{P}^{k}\right\| \leq \varepsilon,\left\|r_{D}^{k}\right\| \leq \varepsilon,\left(x^{k}\right)^{T} s^{k} \leq \varepsilon,
$$

5. Compute the direction by using (A1) - (A4).

6. Compute the step size by using (A5) - (A7).

7. Update

$$
x^{k+1}=x^{k}+\alpha_{k} d_{x}, \quad y^{k+1}=y^{k}+\alpha_{k} d_{y}, \quad s^{k+1}=s^{k}+\alpha_{k} d_{s} .
$$

8. Set $k=k+1$ and go to step 3 .

\subsection{Action research}

An important and integral part in implementing the course was action research methodology $[4,5]$. First, activities that led to desired changes in improving practice based on set objectives were identified. Subsequently, systematic data collection was needed to improve the quality of the teaching process, which had to be included in the action research plan. As noted above, the collected data covered student learning outcomes in form of grades. The important part was self-evaluation through questionnaires handed out upon completion of each course cycle.

The self-evaluation questionnaire posed questions regarding student autonomy in solving assignments throughout all three cycles, general satisfaction with the course, evaluation of their contribution to the research, quizzes on linear programming methods and the final test.

Action research has an elasticity property, meaning that the research plan (outline) may change while implementing the action, and whenever circumstances require change $[13,14]$. This is the reason why research was planned to take place in cycles, giving participants enough time for problem solving and improving the flow of planned activities.

Another characteristic of action research is that it improves teaching. Action research is carried out in a researcher's professional or life context and there is almost universal consensus that action research is not conducted on people, but instead with people. Teachers are often unable to recognize problems in their work processes, preventing them from improving their teaching. Therefore, the recommendation in action research is to seek 
critical friends in other colleagues. A critical friend is a person who usually shares a professional interest and helps the practitioner in achieving the action research, while providing advice and feedback. A critical friend can also be an immediate colleague at work. However, feedback from critical friends should critically accepted and evaluated. Furthermore, action research is a combination of action and research. The school teaching process is action whereas data collection and analysis, including the preparation of reports is considered research. Action involves data collection, and that specific action is followed by data analysis and preparation of reports. When envolved in action research, students become familiar with the objectives, learning outcomes, and the activities expected of them.

In our project, there were three learning cycles as detailed in the previous section. Classes were filmed by video camera and photographed during each cycle. Examples of the teaching activities carried out in Class1 can be seen on YouTube: https://www.youtube.com/watch?v=9Hta7CqhHPg.

\subsection{Samples of teaching material in learning cycles}

Shown in Table 1 below are samples of work by students in learning cycles for both groups. As already noted for Class 1, the course was taught using ICT tools for distance learning, specifically Moodle Loomen, whereas Class2 was taught the course in a traditional manner, using a board and assignments in paper form.

In the first learning cycle, Class 1 used the dynamic geometry software tool GeoGebra to help draw a feasible region and level lines for a particular twodimensional LP problem. A nice feature of GeoGebra is the ability to move a level line of an objective function and track the maximal or minimal value in which vertex of the feasible region.

In the second cycle, students studied how to solve LP problems using the simplex method in tabular form. The tables were custom built in MS Word for students to use in Class 1. In the third cycle, students studied a newer method of solving LP problems called the interior-point method (IPM). In Class 1, they again used MS Word to help them solve the systems and present the results. The reason why MS Word was used was to assure that the amount and nature of the work for both groups was at the same level. Calculating the tables and systems for both the simplex method and the interior-point method can be streamlined and "automated" using other software tools such as Excel or MathLab. We plan to incorporate this option into the module for more advanced student groups that possess a good background in linear algebra and linear system solving, and therefore skip this section and concentrate on the main concepts of both methods. 


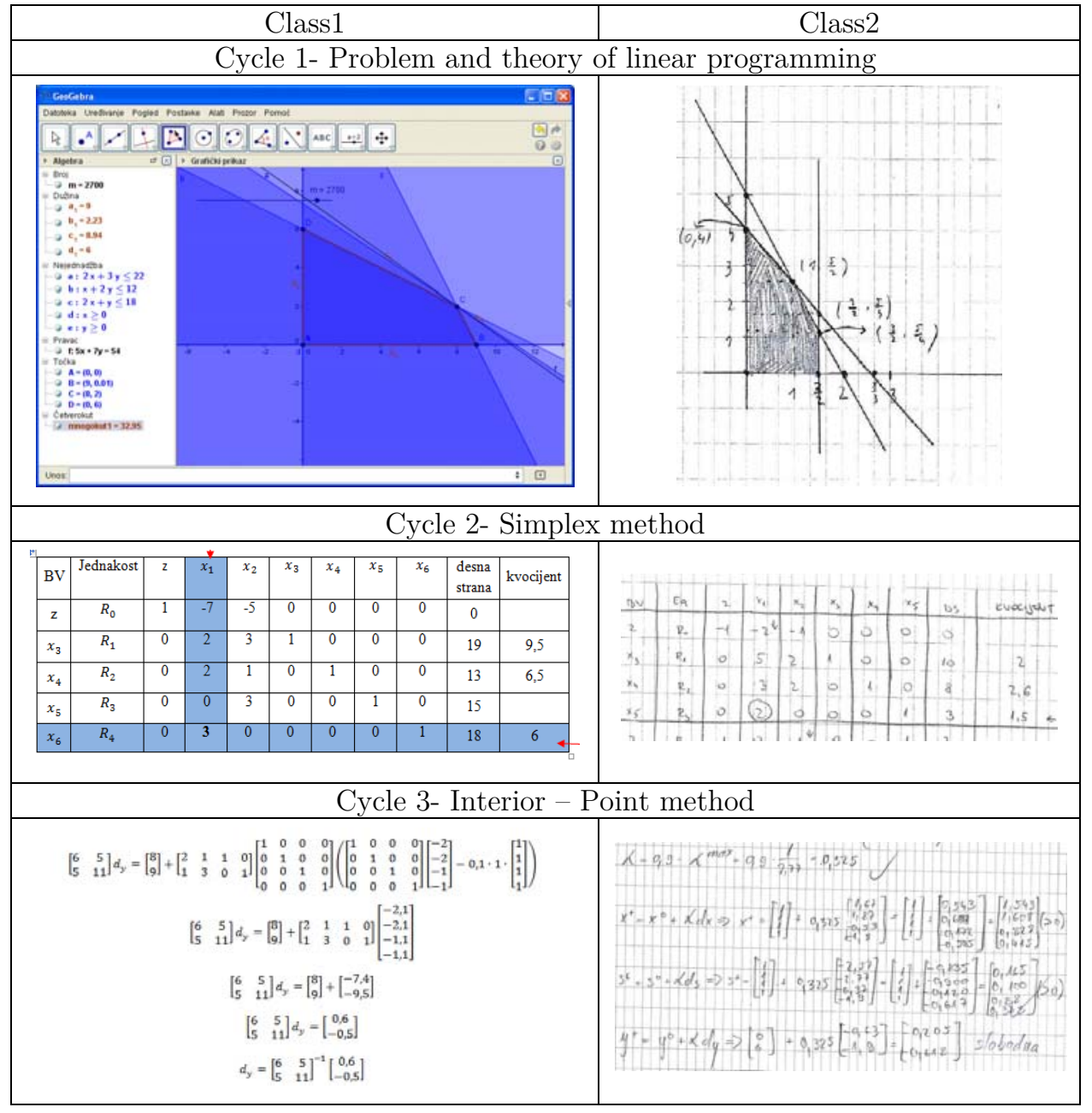

Table 1: Samples of learning material in learning cycles

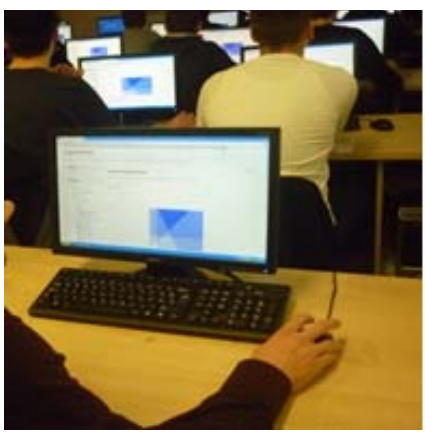

a) Class 1

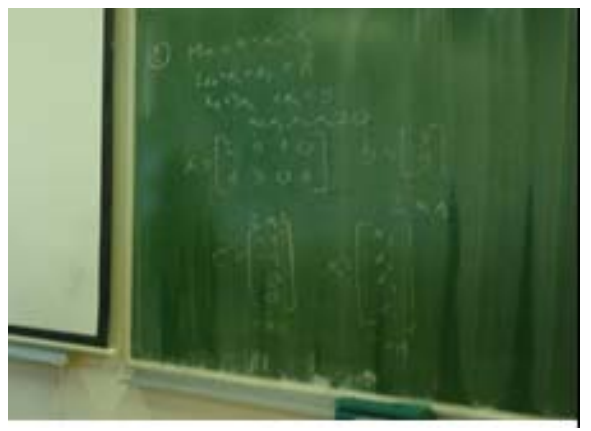

b) Class 2

Figure 1: Photographs of the teaching process in Class 1 and Class 2 


\subsection{Sampling procedure and variables}

As already stated, the created course on linear programming was taught in two classes, Class1 and Class 2 at the Požega High School. Both classes were approximately the same size; Class 1 had 31 students and Class 2 had 29 students. The course was taught in Class 1 with the aid of an ICT tool for distance learning called Moodle Loomen. Class2 was taught the course in a traditional manner, using a board and assignments in paper form. In addition, action research, described in more detail below, was carried out in both classes. Thus, the work in these two classes differs only in regards to one particular component, and that is, the manner in which the course was taught. As the research demanded a certain level of quality, two "equal" groups of students were required. Accordingly, we recorded the initial knowledge of students. The data included their grades in mathematics, computer science, and overall success in the first year, as well as their grades in mathematics and computer science at the end of the first semester of their sophomore year. The additional important components were knowledge of informatics and linear functions. After conducting a statistical test of difference in means and proportions, the conclusion was that the difference between these two student groups is negligible, meaning and we could proceed with the research.

The tracked measurable variables included points (grades) from the students' homework, quizzes, and tests. After completing each teaching cycle, students filled out a questionnaire on assessing the respective cycle, and they also participated in a group interview. Lickert scale was used to obtain values for the questionnaire responses, and relevant data was analyzed.

\subsection{Statistical methods}

Statistical analysis was performed on the collected quantitative data. The method incorporated basic statistical measures such as mean, median, standard deviation, and covariance. Statistical hypothesis testing was also performed using t-test. In assessing the teaching, the Likert scale with five degrees of intensity was applied. A research diary was updated each day. Group interviews were conducted with the students who were asked to complete the questionnaires. Further, the teaching process was photographed and videotaped with the permission of parents.

Action research uses more qualitative data. The main goal of action research is to promote the teaching practiceand it is essential that it be carried out with students. During the action research, data was to be deliberately and systematically collected on everything that happens. In particular, an important source of information in action research is the research diary. Action research is 
carried out in a spiral form amending the basic stages: planning, action, observation and reflection.

A range of points for obtaining a certain grade for each test and final exam was determined. Assignments were graded equally for both groups. Based on the number of obtained points for each test, students received their individual grades. A final grade was then calculated as the arithmetic mean of the grades from three tests after the completion of each cycle and the final exam.

\section{Results}

The final grades for students from both groups are shown in Table 2, as well as the arithmetic means and standard deviations.

\begin{tabular}{|c|c|c|}
\hline Grades & Class 1 & Class 2 \\
\hline 5 & 11 & 8 \\
\hline 4 & 14 & 4 \\
\hline 3 & 6 & 8 \\
\hline 2 & 0 & 0 \\
\hline 1 & 0 & 29 \\
\hline Number of students & 31 & 3.38 \\
\hline Arithmetic Mean & 4.16 & 1.187 \\
\hline Standard Deviation & 0.723 & \\
\hline
\end{tabular}

Table 2: Final evaluations after research

In order to test whether there is a significant difference between the two arithmetic means in Table 1, the t-test was performed such that:

$$
\begin{aligned}
& t=\frac{\bar{X}_{d}}{s_{d}}=\frac{\bar{X}_{1}-\bar{X}_{2}}{\sqrt{\frac{s_{1}^{2}}{N_{1}}+\frac{s_{2}^{2}}{N_{2}}}} \\
& \text { where } \bar{X}_{1}=4.16, \quad \bar{X}_{2}=3.38, s_{1}=0.723, s_{2}=1.187, N_{1}=31, N_{2}=29
\end{aligned}
$$

The degree of freedom is determined as $n_{1}+n_{2}-2=31+29-2=58$.

The resulting $t$ value was 3.058 , which is larger than the theoretical value of $\mathrm{t}=2.00$ for student distribution, while the $p$ value was 0.004 . Thus, the arithmetic mean of the two samples differ significantly at the $5 \%$ level, i.e. the difference between the means of the two grades is statistically significant. Figure 2 and 3 provide a graphical presentation of the grade distribution. 
Research and evaluation of the effectiveness of e-learning in the case of linear programming 121

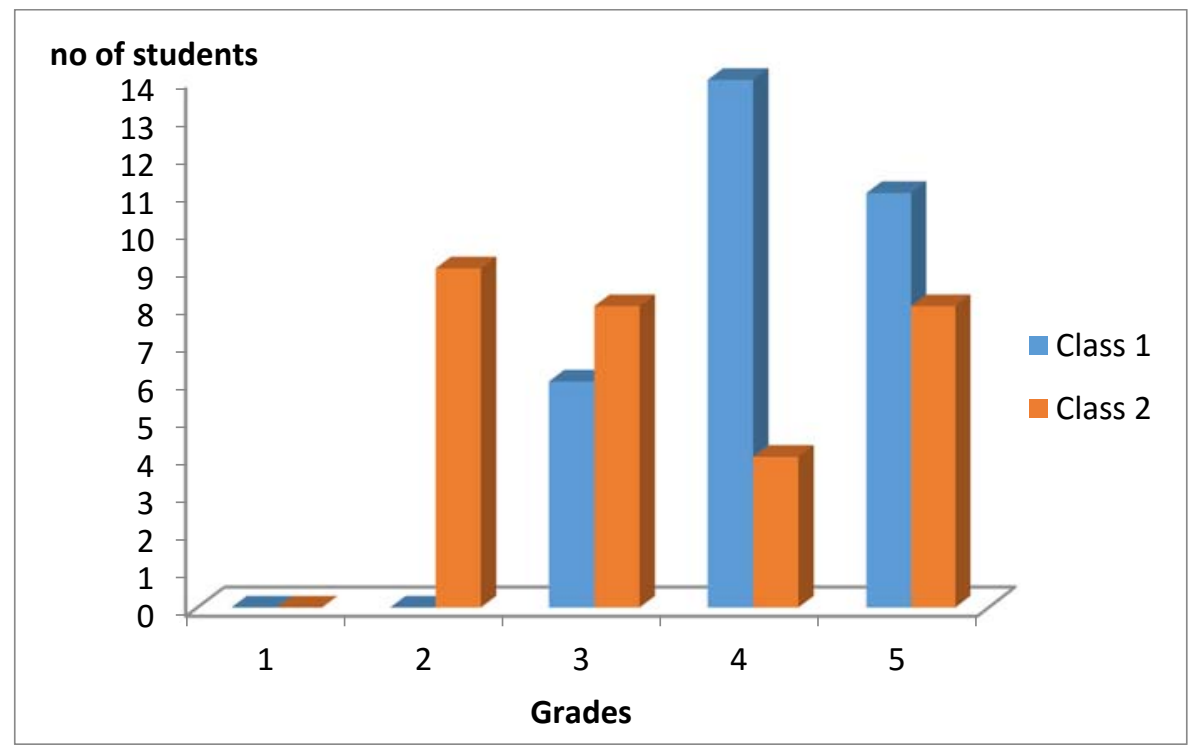

Figure 2: Distribution of grades in two classes

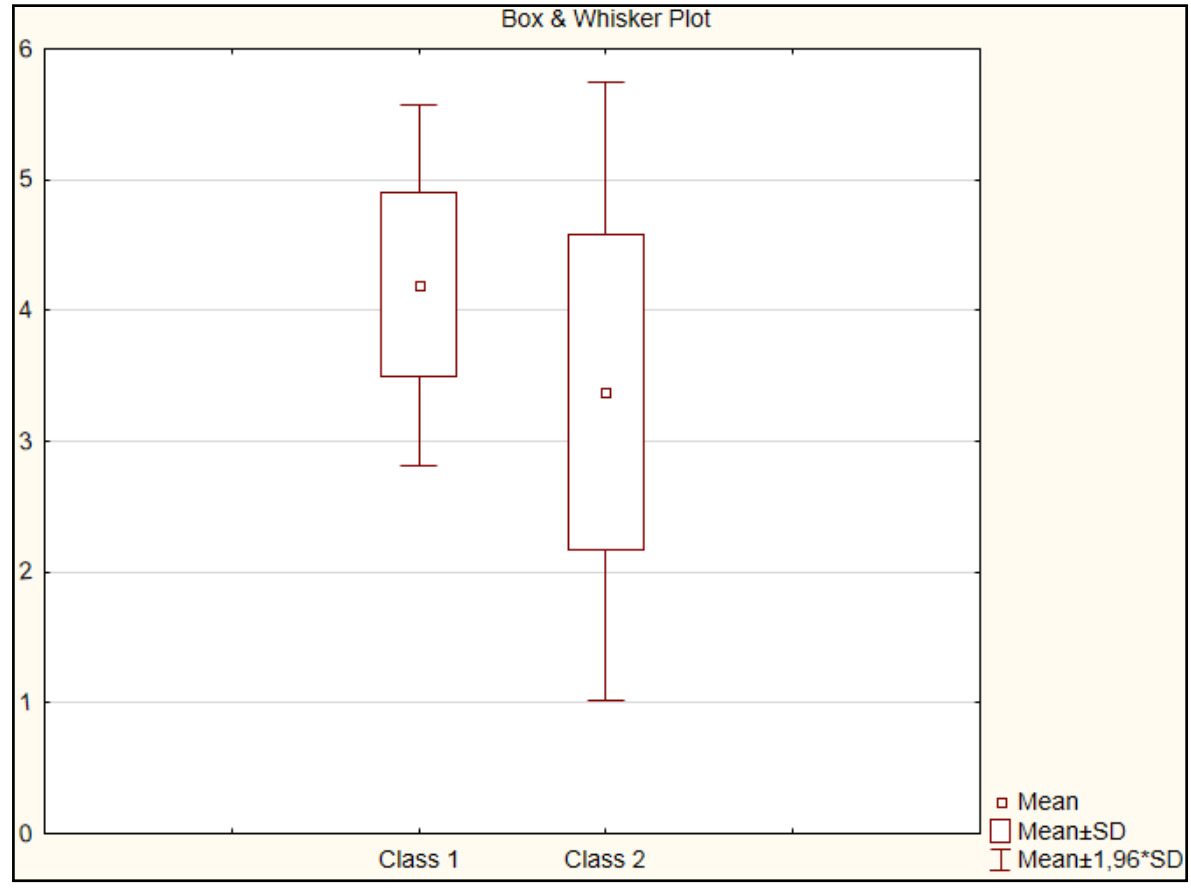

Figure 3: Box-Whisker graph for the average grades between two classes 
Distribution of student responses in the final questionnaire is shown in Table 2.

\begin{tabular}{|c|c|c|c|c|c|c|}
\hline & Statement & $\begin{array}{l}\text { Does not } \\
\text { agree at } \\
\text { all }\end{array}$ & $\begin{array}{c}\text { Mostly does } \\
\text { not agree }\end{array}$ & Indifferent & $\begin{array}{l}\text { Mostly } \\
\text { agree }\end{array}$ & $\begin{array}{l}\text { Fully } \\
\text { agree }\end{array}$ \\
\hline \multicolumn{7}{|c|}{ Cycle 1} \\
\hline 1. & $\begin{array}{l}\text { I solved } \\
\text { homework } \\
\text { by myself- } \\
\text { First cycle }\end{array}$ & $\begin{array}{c}\text { Class 1: } \\
0.00 \% \\
\text { Class 2: } \\
10.34 \% \\
\end{array}$ & $\begin{array}{c}\text { Class 1: } \\
3.26 \% \\
\text { Class 2: } \\
0.00 \%\end{array}$ & $\begin{array}{c}\text { Class 1: } \\
12.90 \% \\
\text { Class 2: } \\
6.90 \% \\
\end{array}$ & $\begin{array}{l}\text { Class 1: } \\
29.03 \% \\
\text { Class 2: } \\
38.71 \% \\
\end{array}$ & $\begin{array}{l}\text { Class 1: } \\
54.89 \% \\
\text { Class 2: } \\
38.71 \% \\
\end{array}$ \\
\hline \multicolumn{7}{|c|}{ Cycle 2} \\
\hline 2. & $\begin{array}{l}\text { I solved } \\
\text { homework } \\
\text { by myself- } \\
\text { Second cycle } \\
\end{array}$ & $\begin{array}{c}\text { Class 1: } \\
3.24 \% \\
\text { Class 2: } \\
10.34 \% \\
\end{array}$ & $\begin{array}{c}\text { Class 1: } \\
0.00 \% \\
\text { Class 2: } \\
3.45 \% \\
\end{array}$ & $\begin{array}{l}\text { Class 1: } \\
16.13 \% \\
\text { Class 2: } \\
20.69 \% \\
\end{array}$ & $\begin{array}{l}\text { Class 1: } \\
29.03 \% \\
\text { Class 2: } \\
27.59 \% \\
\end{array}$ & $\begin{array}{l}\text { Class 1: } \\
51.61 \% \\
\text { Class 2: } \\
37.93 \% \\
\end{array}$ \\
\hline \multicolumn{7}{|c|}{ Cycle 3} \\
\hline 3. & $\begin{array}{l}\text { I solved } \\
\text { homework } \\
\text { by myself- } \\
\text { Thrid cycle }\end{array}$ & $\begin{array}{c}\text { Class 1: } \\
3.23 \% \\
\text { Class 2: } \\
6.90 \% \\
\end{array}$ & $\begin{array}{c}\text { Class 1: } \\
0.00 \% \\
\text { Class 2: } \\
3.45 \% \\
\end{array}$ & $\begin{array}{l}\text { Class 1: } \\
16.13 \% \\
\text { Class 2: } \\
10.34 \% \\
\end{array}$ & $\begin{array}{l}\text { Class 1: } \\
22.58 \% \\
\text { Class 2: } \\
37.93 \%\end{array}$ & $\begin{array}{c}\text { Class 1: } \\
58.06 \% \\
\text { Class 2: } \\
41.38 \% \\
\end{array}$ \\
\hline \multicolumn{7}{|c|}{ Final Exam } \\
\hline 4. & $\begin{array}{l}\text { I solved } \\
\text { Final exam } \\
\text { by myself }\end{array}$ & $\begin{array}{c}\text { Class 1: } \\
0.00 \% \\
\text { Class 2: } \\
6.90 \%\end{array}$ & $\begin{array}{c}\text { Class 1: } \\
0.00 \% \\
\text { Class 2: } \\
0.00 \% \\
\end{array}$ & $\begin{array}{c}\text { Class 1: } \\
6.45 \% \\
\text { Class 2: } \\
17.24 \% \\
\end{array}$ & $\begin{array}{l}\text { Class 1: } \\
29.03 \% \\
\text { Class 2: } \\
34.48 \%\end{array}$ & $\begin{array}{l}\text { Class 1: } \\
64.52 \% \\
\text { Class 2: } \\
41.38 \%\end{array}$ \\
\hline 5. & $\begin{array}{l}\text { Asses your } \\
\text { way of } \\
\text { following the } \\
\text { action } \\
\text { research }\end{array}$ & $\begin{array}{c}\text { Class 1: } \\
0.00 \% \\
\text { Class 2: } \\
6.90 \%\end{array}$ & $\begin{array}{c}\text { Class 1: } \\
0.00 \% \\
\text { Class 2: } \\
6.90 \%\end{array}$ & $\begin{array}{l}\text { Class 1: } \\
32.26 \% \\
\text { Class 2: } \\
17.23 \%\end{array}$ & $\begin{array}{l}\text { Class 1: } \\
58.06 \% \\
\text { Class 2: } \\
41.38 \%\end{array}$ & $\begin{array}{c}\text { Class 1: } \\
9.69 \% \\
\text { Class 2: } \\
27.59 \%\end{array}$ \\
\hline 6. & $\begin{array}{l}\text { Asses your } \\
\text { contribution } \\
\text { to the action } \\
\text { research }\end{array}$ & $\begin{array}{c}\text { Class 1: } \\
0.00 \% \\
\text { Class 2: } \\
17.24 \%\end{array}$ & $\begin{array}{c}\text { Class 1: } \\
12.90 \% \\
\text { Class 2: } \\
3.45 \%\end{array}$ & $\begin{array}{l}\text { Class 1: } \\
29.03 \% \\
\text { Class 2: } \\
41.38 \%\end{array}$ & $\begin{array}{l}\text { Class 1: } \\
48.39 \% \\
\text { Class 2: } \\
24.14 \%\end{array}$ & $\begin{array}{c}\text { Class 1: } \\
9.68 \% \\
\text { Class 2: } \\
13.79 \%\end{array}$ \\
\hline 8. & $\begin{array}{l}\text { Are you } \\
\text { satisfied } \\
\text { with the } \\
\text { course? }\end{array}$ & $\begin{array}{c}\text { Class 1: } \\
3.23 \% \\
\text { Class 2: } \\
6.90 \% \\
\end{array}$ & $\begin{array}{c}\text { Class 1: } \\
3.23 \% \\
\text { Class 2: } \\
10.34 \% \\
\end{array}$ & $\begin{array}{l}\text { Class 1: } \\
16.13 \% \\
\text { Class 2: } \\
17.24 \% \\
\end{array}$ & $\begin{array}{l}\text { Class 1: } \\
48.39 \% \\
\text { Class 2: } \\
31.04 \% \\
\end{array}$ & $\begin{array}{l}\text { Class 1: } \\
29.02 \% \\
\text { Class 2: } \\
34.48 \% \\
\end{array}$ \\
\hline & Statement & 1 & 2 & 3 & 4 & 5 \\
\hline 7. & $\begin{array}{l}\text { If allowed, } \\
\text { what grade } \\
\text { you would } \\
\text { give to } \\
\text { yourself }\end{array}$ & $\begin{array}{ll}\text { Class } & 1: \\
0.00 \% & \\
\text { Class } & 2: \\
0.00 \% & \end{array}$ & $\begin{array}{ll}\text { Class } & \text { 1: } \\
3.23 \% & \\
\text { Class } & 2: \\
10.34 \% & \end{array}$ & $\begin{array}{ll}\text { Class } & 1: \\
3.23 \% & \\
\text { Class } & 2: \\
27.59 \% & \end{array}$ & $\begin{array}{l}\text { Class 1: } \\
41.94 \% \\
\text { Class 2: } \\
24.14 \%\end{array}$ & $\begin{array}{l}\text { Class 1: } \\
51.60 \% \\
\text { Class 2: } \\
37.93 \%\end{array}$ \\
\hline
\end{tabular}

Table 3: Distribution of responses after the conducted questionnaires 
As is evident in Table 3, a higher percentage of students from Class 1 than Class 2 solved the assignments and the final exam independently. Also, more students in Class 1 evaluated themselves with higher grades (4 or 5) than students in Class 2.

Class 1 expressed a percentagewise stronger satisfaction with the course (77.41\% of students in Class 1 mostly agreed or fully agreed that they were satisfied with the course compared to $65.52 \%$ of students in Class 2). This conforms to the fact that their success in the course was better than that of Class 2. In Class 1, 90.32\% of students would participate again in a similar course with the same format and action research methodology, while only $79.31 \%$ of students in Class 2 would do the same. In addition to the above questions, students were asked to write down their general opinion of the way they were exposed to learning. Students in Class 1 commented that they liked online learning, emphasizing the ease of accessing the teaching materials even out of class, and they liked the online exams. Students in Class 2 generally liked the opportunity to learn new methods, and they liked to work in teams, but they felt stressed by the limitations of having a lot of paper material which was hard to learn.

\section{Comments and discussion}

Both student groups felt that the course was presented in a useful and interesting manner, and that they learned a lot about a subject which otherwise is not part of their standard curriculum. Most of them liked the action research methodology and thought the approach enabled them to participate more actively in the learning process.

Students in both classes thought the second cycle of the course was the hardest and most time consuming. Students in Class 1 liked the first cycle the most and the main reason was the use of the GeoGebra software package used to solve problems. Students in Class 2 liked the second cycle the most and the main reason was the interactive use of simplex tables drawn on the board.

In addition, the student group that used e-learning (Class 1) expressed additional satisfaction in using e-learning methods due to the ease of accessing the content, flexibility and convenience in writing homework, doing the quizzes and tests using computers and the paperless way of communicating. They claimed that e-learning facilitated learning and increased success in class. Even the group that used classical learning techniques (Class 2) expressed a desire to use e-learning.

Critical friends provided positive comments on the design and execution of the project. The first critical friend had doubts at the beginning of the project as to whether it was possible to teach the advanced topic effectively, especially 
to high school sophomores. However, during the course of the project, the friend was surprised as to how well students responded and learned, at times, new challenging material. Success was attributed to the exceptionally well designed course, the novel use of ICT, and creative use of the action research methodology. The second critical friend noticed methodological challenges in setting up two parallel versions of the course and making sure they differ only in one component, that is, the use of ICT. The friend also noticed the challenge posed in forming two sample student groups with statistically negligible differences at the beginning of the project for all categories relevant for the research. The friend observed that these challenges were resolved diligently and effectively in accordance with scientific guidelines for designing the test samples. The opinion was that these appropriate methodological solutions, coupled with well-planned and consistent action research during execution of the project, contributed to the success of the project and validity of the findings.

The experiences and findings of the project were presented at several seminars and workshops for high school teachers. The feedback was positive. Several teachers expressed an opinion that the project could possibly serve as a model for teaching advanced, nonstandard topics, not part of the standard curriculum, and not only mathematics but in other subjects as well. Some of the teachers were interested in getting access to the online module and possibly experimenting with a similar course in their own schools.

The issue that was brought up in discussion at some of the workshops and seminars was a concern that the majority of teachers in Croatia are not trained and ready to use ICT on a regular basis. Transition and adoption of ICT and elearning may be easier for students than for some teachers, which is understandable given that the younger generation is growing up surrounded by ICT to which they adopt quickly. Comments and our own assessment suggest two directions in which the project and future research can be improved. The test samples, that is, the groups of students participating in the project, were limited due to various circumstances. This was mainly because research was not sponsored by any organization, rather it was an individual effort. Certainly, larger test samples would have been more desirable; however, mechanisms that were used in forming two student groups with equal background knowledge and learning potential were implemented very carefully to assure the validity of the findings at the end of the project. We are confident that the results of our research would stand, and possibly be even more transparent, with larger test samples. Nevertheless, having larger test samples and more groups of students would allow for consideration of additional research questions. For example, it would be interesting to compare the performance of two groups of students who use e-learning but one group of students have face-to-face access to the instructor while the other group does not. Another way in which the project can be improved is expanding the on-line module of lectures with additional material, innovative examples and problems, and the inclusion of more software 
tools such as Excel and Matlab. Furthermore, it would be helpful to work on the design of a better, more user-friendly interface. The goal is to develop an online course that would be self-sustained and easy to use for other instructors as well as students.

\section{Concluding remarks}

In this paper, we have described and evaluated a project to research the effectiveness of e-learning in linear programming. The goal of the project was to investigate whether and how proper use of information and communication technologies, as well as interactive learning helps students to understanding, learning and retain taught material. The initial hypothesis was that it does.

In the first phase of research, a module lesson for linear programming (LP) was devised using the software package Loomen Moodle and other interactive software packages such as Geogebra. In addition to traditional content, such as the simplex method, the module also contained a chapter on new LP methods called the interior points method (IPM).

In the second phase, research was carried out to examine the effectiveness of e-learning using the created LP module as an example. The LP module was taught as a short course to two groups of students. These two groups of students were second-graders in a Croatian high school. In Class 1, the module was taught using e-learning, whereas Class 2 was taught using traditional methods.

During the course of the research, the data were collected, analyzed and evaluated. The methodology for the project and data collection is called "action research", which recently has been gaining in popularity. This methodology emphasizes the importance of both quantitative and qualitative data collection. The qualitative data collection relies on the research diary, interviews, questionnaires, Likert's evaluation scale, systematic observations, collection of visual data from photos and videos taken of the teaching process. The quantitative data collection include the results of homework, quizzes and tests. Statistical analysis of quantitative data was performed utilizing basic statistical tools such as mean, median, standard deviation, covariance and statistical hypothesis testing using t-test.

Statistical analysis showed that the group of students who used e-learning showed better results than the group that used traditional learning methods. Thus, the initial hypothesis was validated. Furthermore, in their feedback students expressed satisfaction with the project and the way it was conducted.

As far as we are aware, this research is novel in several aspects. It showed that advanced topics, such as linear programing, can be taught effectively and successfully to high school students. An appropriate "model" is suggested, developed and tested. The integral part of the design and the delivery of the 
course is action research, which in our opinion contributed greatly to the success of the project. Basic but rigorous statistical analysis was used to validate the hypothesis that appropriate use of ICT and e-learning is more effective than the traditional learning methods in such settings.

The proposed model serves as an example for developing on-line courses in mathematics and other areas, especially for topics that are not an integral part of standard high-school curriculum. This research supports a more general thesis, which is that the future of successful learning by new generations of students will depend on a more intensive use of ICT and e-learning. This will definitely require additional efforts by teachers and the entire educational system, but we are adamant that the investment will eventually pay off and lead us into a better future.

\section{References}

[1] All, A., Nuñez Castellar E. P., Van Looy, J. (2016). Assessing the effectiveness of digital game-based learning: Best practices. Computers \& Education, 92-93, 90-103.

[2] Babic, S. (2009). Introduction to e-learning, look through the window. Available at: https://pogledkrozprozor.wordpress.com/2009/08/29/uvod-u-e-\%E2\%80\%93learning-1-dio/ [Accessed on July 13, 2014].

[3] Bjelanović Dijanic, Ž. (2011). Learning mathematics detection with the help of dynamic geometry software GeoGebra - Action Research. The Third International Scientific Colloquium "Mathematics and Children" - The Math Teacher, Osijek.

Available at: http://free-bj.t-

com.hr/zbjelanovic/radovi/akcijsko_istrazivanje_GeoGebra.pdf [Accessed on July 13, 2014].

[4] Bognar, B. (2006). Action research in school. Educational sciences, 8(1), 209-227.

[5] Bognar, B. (2013). Initiating teacher's action research: Empowering teachers' voices. Educational Journal of Living Theories. 6(1), 1-39.

[6] Bognar, B. (2008). Possibility of becoming the teacher - action researcher through electronic learning (doctoral dissertation, University of Zagreb). Available at: http://kreativnost.pedagogija.net/file.php/1/Dokumenti/ddisertacija_kraj.p df [Accessed on July 13, 2014].

[7] Dečman, M. (2015). Modeling the acceptance of e-learning in mandatory environments of higher education: The influence of previous education and gender, Computers in Human Behavior, 49, 272-281.

[8] Lester, J. Designing interactive mathematics. Available at: http://www.cecm.sfu.ca/ jalester/DesignIntMath.pdf [Accessed on July 13, 2014].

[9] Lesaja, G. (2009). Introducing Interior-Point Methods for introductory operations research courses and/or linear programming courses. Open Operational Research Journal, 3: 1-12. Available at: http://digitalcommons.georgiasouthern.edu/mathsci-facpubs/77 [Accessed on July 13, 2014].

[10] Lešaja, G., Drummer A. Miletic, Lj. (2012). Full infeasible Newton-Step InteriorPoint Method for linear complementarity problems. Croatian Operational Research Review (CRORR), 3(1), 163-176. 
[11] Matijevic, M. (1990). Action research and the reform of elementary school. In the monograph: Action research in educational process, Slovenian pedagogical society, Ljubljana, pp. 78-87.

[12] Matijevic, M., Radovanovic, D. Teaching focused on students. The School Newspaper, Zagreb, 2011.

[13] Ministry of Science, Education and Sports. The full text of the strategy for education, science and technology. Available at: http://public.mzos.hr/fgs.axd?id=22355 [Accessed on July 13, 2014].

[14] Muzic, V. (1999). Introduction to Research Methodology Education. Educa, Zagreb.

[15] Neralic, L. (2012). Introduction to Mathematical Programming 1, Fourth Edition. Element, Zagreb.

[16] Secondary school Marko Marulic Slatina. Uvođenje e-učenja (Introducing elearning). Available at:

http://ss-mmarulica-slatina.skole.hr/uvodjenje_e_ucenja [Accessed on July 13, 2014].

[17] Yanusik, O. V., Pakhomova, E. G., Batbold, K. (2015). E-learning as a way to improve the quality of educational for international students, Procedia - Social and Behavioral Sciences, 215, 147-155. 